\title{
Reactivity Studies of $\beta$-Alkene-type Porphyrins with Vinyl- Triazoles by Cross Metathesis Reactions
}

\author{
Ana T.P.C. Gomes ${ }^{a}$, Fernando de C. da Silva ${ }^{b}$, Maria G.P.M.S. Neves ${ }^{a}$, Augusto \\ C.Tomé $^{\mathrm{a}}$, Artur M.S. Silva ${ }^{\mathrm{a}}$, Vítor F. Ferreira ${ }^{\mathrm{b}}$, José A.S. Cavaleiro ${ }^{\mathrm{a}^{*}}$ \\ ${ }^{a}$ Department of Chemistry and QOPNA, University of Aveiro, 3810-193 Aveiro, Portugal \\ ${ }^{b}$ Departamento de Química Orgânica, Universidade Federal Fluminense, 24020-150 Niterói, RJ, Brazil \\ *E-mail:jcavaleiro@ua.pt
}

Keywords: Porphyrin, Triazole, Metathesis Reaction

\section{INTRODUCTION}

The search for new tetrapyrrolic macrocycles with adequate features for specific applications (e.g. cancer photodynamic therapy, microorganisms photoinactivation, catalysis, electronics, solar cells production, etc.) has become a target for several research groups. ${ }^{1}$ Recently several approaches were explored for developing, or improving, methods to obtain novel porphyrin derivatives. Diels-Alder, 1,3-dipolar cycloadditions, electrocyclization and cyclopropanation reactions are examples of that. ${ }^{2}$ In this communication we will report our studies on the reactivity of $\beta$-alkene-type porphyrins with several vinyl-triazoles through metathesis methodologies.

\section{RESULTS AND DISCUSSION}

We decided to start this study with the reaction of the zinc complex of $\beta$-vinyl-5,10,15,20tetraphenylporphyrin 1 with vinyl-triazoles $2 a-e$ in the presence of $2^{\text {nd }}$ Generation Grubbs Catalyst. In these reactions we were able to isolate the triazolesubstituted porphyrins 3a-e (Scheme 1).

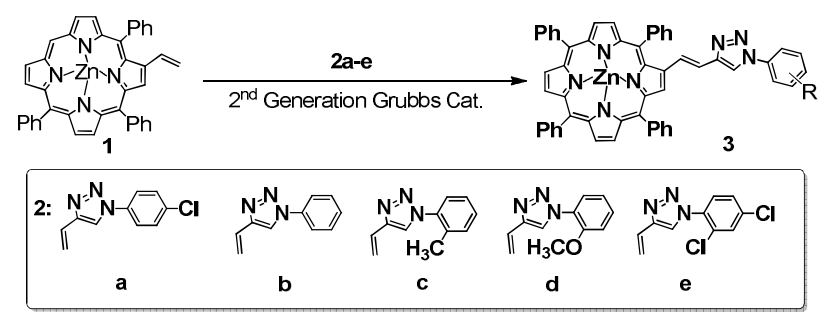

Scheme 1. Metathesis reaction of porphyrin 1 with vinyltriazoles 2a-e in the presence of $2^{\text {nd }}$ Generation Grubbs Catalyst.

We observed that the yields of these reactions are usually low (9-26\%). So we have decided to use a different porphyrin with two conjugated double bonds in a $\beta$-pyrrolic position, the nickel complex of 2-(1,3-butadienyl)-5,10,15,20-tetraphenylporphyrin,

$\mathbf{4}$, in the metathesis reaction with vinyl-triazoles $\mathbf{2 a -}$ e. In this way the reactions afforded the isomeric triazole-substituted porphyrins 5 (trans,trans) and 6 (trans,cis) with global yields higher than those obtained for porphyrin 1 (table 1).

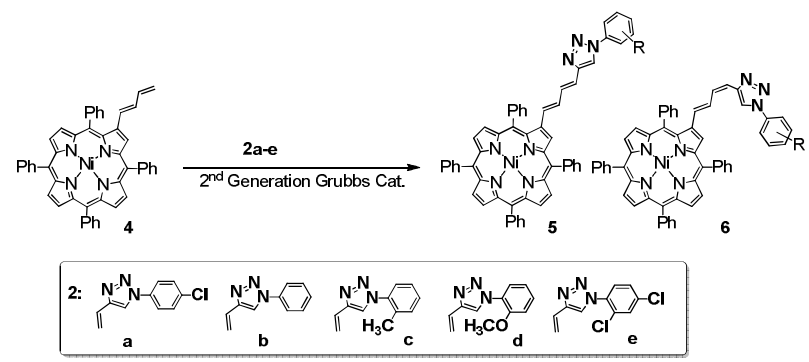

Scheme 2. Metathesis reaction of porphyrin 4 with vinyltriazoles $2 \mathrm{a}-\mathrm{e}$ in the presence of $2^{\text {nd }}$ generation Grubbs catalyst.

Table 1. Results obtained in the metathesis reaction of porphyrin 4 with vinyl-triazoles $2 a-e$.

\begin{tabular}{cccc}
\hline $\mathbf{4}$ & $\mathbf{5}$ & $\mathbf{6}$ & Global $\square(\%)$ \\
\hline a & 21 & 13 & 34 \\
b & 19 & 16 & 34 \\
c & 9 & 12 & 21 \\
d & 21 & 19 & 40 \\
e & 9 & - & 9 \\
\hline
\end{tabular}

\section{CONCLUSION}

In this work we looked at the reactivity of two $\beta$ alkene-type porphyrins with several vinyl-triazoles under metathesis conditions in the presence of the $2^{\text {nd }}$ Generation Grubbs Catalyst. We observed that porphyrin $\mathbf{4}$ is more reactive then porphyrin $\mathbf{1}$ affording isomeric compounds $\mathbf{5}$ and $\mathbf{6}$ in acceptable yields. This methodology allows the synthesis of novel triazole-substituted porphyrin derivatives which might exhibit important biological activities.

\section{ACKNOWLEDGEMENTS}

Thanks are due to the University of Aveiro, Fundação para a Ciência e a Tecnologia and FEDER for funding the Organic Chemistry Research Unit and the FCT-CAPES collaborative programme for funding this work. ATPC Gomes thanks FCT for her PhD grant (SFRH/BD/38528/2007).

\section{REFERENCES}

${ }^{1}$ Kadish, K.M., Smith, K.M.; Guilard, R. Handbook of Porphyrin Science, World Scientific Publishing Company Co:Singapore, 2010, vol. 1-12.

2 Cavaleiro, J.A.S., Tomé, A.C.; Neves, M.G.P.M.S.; Handbook of Porphyrin Science, vol. 2, World Scientific Publishing Co.: Singapore, 2010. 